\title{
Risk of coronary artery disease in individuals infected with human immunodeficiency virus
}

\begin{abstract}
Current treatment for human immunodeficiency virus (HIV) infection has improved survival and allowed infected patients to develop atherosclerotic coronary artery disease (CAD). Specific strategies to reduce cardiovascular risk in the infected population have not been developed. It is necessary to know the magnitude of cardiovascular risk in this population. Objectives: This study aimed to assess cardiovascular risk using a well-known clinical score and to investigate coronary artery calcium scoring (CACS) in this population. Methods: This was a cross-sectional study. Adults with HIV infection were studied. Demographic, clinical and anthropometric data, serum glucose and lipids were obtained. Cardiovascular risk was calculated through Framingham risk score (FRS) and CACS. Categorical variables were compared by Chi-square or Fisher's exact test, and continuous variables were analyzed by Student $t$ test or Mann-Whitney test. An analysis of concordance between FRS and CACS was performed using kappa statistic. Results: Forty patients, aged $45.9 \pm 8.1$ years, were studied. Age of risk for CAD were found in $30.0 \%$, hypertension in $55.0 \%$, diabetes in $10.0 \%$, smoking in $35.0 \%$, dyslipidemia in $67.5 \%$ and family history of CAD in $57.5 \%$. Altered levels of total cholesterol, LDL-cholesterol, HDL-cholesterol and triglycerides were found in 30.0\%, 25.0\% and $82.5 \%$, respectively. HDL-cholesterol and triglycerides were altered more frequently among protease inhibitors users. The FRS classified the risk as low for $72.5 \%$, moderate for $25.0 \%$, and high for $2.5 \%$. CACS $>0$ was found in $32.5 \%$ of the patients, in $67.5 \%$ the score was low, in $17.5 \%$ moderate, and in $15.0 \%$ high. Concordance between FRS and CACS showed a kappa $=0.435$. Conclusions: There is a high prevalence of risk factors for CAD in the studied population, with dyslipidemia being the most frequent. HDL-cholesterol and triglycerides were the most frequently altered factors and were associated with the use of protease inhibitors. Risk assessed by the FRS was low in most cases. CACS $>0$ was found in $32.5 \%$, demonstrating the need to re-evaluate the strategies for assessing cardiovascular risk in the HIV-infected population.
\end{abstract}

Keywords: coronary artery disease; HIV; cardiovascular diseases; HIV protease inhibitors.

\section{INTRODUCTION}

Infection with human immunodeficiency virus (HIV) is a public health problem worldwide. In 2009, the United Nations estimated that worldwide 33.3 million people were infected with HIV, being 1.4 million in South and Central Americas. ${ }^{1}$ In Brazil, updated data up to June 2010 accounted for 592,914 cases of acquired immunodeficiency syndrome (AIDS) reported since 1980, with 38,538 new cases reported in 2009.,3 Public expenditures with hospitalizations and complications due to AIDS in Brazil amounted to about 8.2 million dollars in 2008 only, confirming the magnitude of the problem. ${ }^{3-5}$
Since 1996, with the advent of new antiretroviral therapies (ART), there have been significant gains in the fight against HIV infection, with increased life expectancy of these patients. ${ }^{4-6}$ This allowed, on the other hand, individuals with HIV infection to develop chronic diseases common to the general population, among which atherosclerotic cardiovascular disease (ACVD), more specifically represented by atherosclerotic coronary artery disease (CAD), started to be highlighted. In the mid-90s, there was emphasis on reports of myocardial infarction (MI) in young patients infected with HIV and the possible association between HIV infection and increased risk of $\mathrm{CAD}^{5-7}$ Subsequent studies confirmed an
Authors

Felippe Dantas Vilela ${ }^{1}$

Andrea Rocha de

Lorenzo $^{2}$

Bernardo Rangel Tura ${ }^{3}$

Giovanna Ianini

Ferraiuoli $^{4}$

Marcelo Hadlich ${ }^{1}$

Marcelo Viana de Lima

Barros $^{5}$

Ana Beatriz Ribeiro Lima

Vanderson Meirelles ${ }^{7}$

${ }^{1}$ Postgraduate in

Cardiology, Instituto

Nacional de Cardiologia,

RJ, Brazil

${ }^{2} \mathrm{PhD}$ in Cardiology,

Universidade Federal do

Rio de Janeiro (UFRJ), RJ,

Brazil

${ }^{3} \mathrm{PhD}$ in Biostatistics, UFRJ,

RJ, Brazil

${ }^{4}$ Professor, Instituto

Nacional de Cardiologia,

RJ, Brazil

${ }^{5}$ Nutritionist, Instituto

Nacional de Cardiologia,

RJ, Brazil

${ }^{6}$ Social Worker, Instituto

Nacional de Cardiologia,

RJ, Brazil

${ }^{7}$ Physician, Instituto

Nacional de Cardiologia,

RJ, Brazil
Submitted on: 02/15/2011 Approved on: 06/27/2011

Correspondence to: Felippe Dantas Vilela Departamento de

Pesquisa Clínica Rua das Laranjeiras, $374 / 5^{\circ}$ - Laranjeiras 22240-006

Rio de Janeiro, RJ

Brazil

felippevilela@gmail.com

We declare no conflict of interest.

(C)2011 Elsevier Editora Ltda. All rights reserved. 
increased incidence of CAD in these individuals and over time, CAD has become a major cause of morbidity and mortality in this population. ${ }^{6-9}$

In the general population, the "IV Brazilian Guidelines on Dyslipidemia and Atherosclerosis Prevention" of the Brazilian Society of Cardiology recommends the use of stratification of cardiovascular risk and sets lipid targets for prevention and treatment of atherosclerosis. ${ }^{8}$ For that purpose, the use of the Framingham Risk Score (FRS) is indicated. The coronary artery calcium scoring (CACS), obtained through computed tomography, is considered an aggravating risk factor for CAD when the individual's percentile adjusted for age and sex is $>75 \% .8,9$

In these guidelines some recommendations are proposed for special groups, such as individuals with HIV infection, for whom the risk assessment for CAD through the FRS and lipid profile is suggested. ${ }^{8}$ The "Recommendations for Antiretroviral Therapy in Adults Infected with HIV: 2008" also recommend that patients with HIV infection should be evaluated in order to identify the degree of cardiovascular risk. The approach is again based on the FRS, respecting some specific characteristics of this group, such as the use of protease inhibitors (PI). ${ }^{10}$ In this population, the use of complementary examinations is suggested, including imaging assessment such as CACS as an attempt to achieve better cardiovascular risk stratification. ${ }^{10}$

\section{MATERIAL AND METHODS}

We studied HIV positive individuals over 18 years of age receiving care at specialized centers for treating HIV-infected patients, who presented no cardiovascular symptoms or history of CAD. By that it is understood: (I) myocardial infarction documented in hospital records or by clinical history associated with diagnostic methods; (II) stable or unstable angina, documented in hospital records, medical report or classical clinical history; (III) asymptomatic ischemic heart disease, but with coronary angiography showing a lesion $>50 \%$ in one or more coronary arteries or cardiac imaging assessment documenting ischemic alterations; (IV) previous CABG surgery; (V) prior coronary angioplasty; (VI) documented cerebrovascular accident; (VII) aortic aneurysmal disease or aortic stenosis; (VIII) peripheral artery disease documented by imaging method.

All patients who agreed to participate were seen by a multidisciplinary team consisting of cardiologists, social worker and nutritionist. Demographic, clinical, and anthropometric data were obtained, including traditional risk factors for cardiovascular disease ${ }^{11-13}$ [age ( $\geq 45$ years for men and $\geq 55$ years for women), smoking (current smoking or stopped within the past 30 days), family history of early CAD (myocardial infarction or death from CAD of first-degree relatives, if male aged $<55$ years and females aged $<65$ years), systemic arterial hypertension ( $\mathrm{SAH}$ with previous diagnosis and/or use of antihypertensive medication), dys- lipidemia (previous diagnosis and/or medication to reduce lipid levels) and diabetes mellitus (DM, with prior diagnosis and/or medication to reduce blood glucose)], current ART and PI use, body mass index (BMI, calculated as the ratio between the weight in kilograms and squared height in meters and considered normal from 18.5 to $24.9 \mathrm{~kg} / \mathrm{m}^{2}$, overweight 25.0 to $29.9 \mathrm{~kg} / \mathrm{m}^{2}$ and obesity $\left.\geq 30.0 \mathrm{~kg} / \mathrm{m}^{2}\right) ; ;^{14,15}$ abdominal circumference (AC, measured in $\mathrm{cm}$, at the umbilicus and considered abnormal when $>10^{2} \mathrm{~cm}$ in men and $>88 \mathrm{~cm}$ in women ${ }^{15-17}$ ), systemic blood pressure measurements at rest, with blood pressure considered to be altered when systolic blood pressure (SBP) levels were $\geq 140 \mathrm{mmHg}$ or if diastolic blood pressure (DBP) levels were $\geq 90$ mmHg. ${ }^{18}$

All patients underwent glucose, triglycerides, HDLcholesterol, LDL-cholesterol and total cholesterol (TC) measurements after a 12-hour fasting period. For female patients of childbearing age, a qualitative beta-human chorionic gonadotropin (beta-HCG) was also performed, due to the subsequent performance of the CT scan, which involves radiation emission.

Serum glucose, TC, LDL-cholesterol and triglycerides were considered abnormal if, respectively, greater than $100 \mathrm{mg} / \mathrm{dL},{ }^{19} 200 \mathrm{mg} / \mathrm{dL}, 100 \mathrm{mg} / \mathrm{dL}$ and $150 \mathrm{mg} / \mathrm{dL}^{11}$; HDL-cholesterol was considered low when less than $40 \mathrm{mg} / \mathrm{dL}$ and altered, according to sex, when $<45 \mathrm{mg} / \mathrm{dL}$ in men and $<55 \mathrm{mg} / \mathrm{dL}$ in women. ${ }^{20}$

The CT scan was performed in a 64-detector CT scanner (Somatom Sensation 64, Siemens) within one week after the collection of laboratory tests. The Agatston score ${ }^{21,22}$ was used in order to measure CACS, ${ }^{23-25}$ and percentiles were generated according to age and sex..24,26 The risk was categorized as "low" when there was no calcium in the coronary arteries (CACS $=0),{ }^{27}$ "moderate" when the CACS was less than or equal to the third quartile $\left(75^{\text {th }}\right.$ percentile $)^{28}$ for age and sex, and "high" when CACS was greater than the third quartile for age and sex. $8,27,28$

The FRS was classified as "low" risk when the rate obtained was $<10 \%$, "moderate" when the percentage was $\geq 10 \%$ and $\leq 20 \%$, and "high" when $>20 \% .{ }^{8,29,30}$ Variables with normal distribution were expressed as mean \pm standard deviation, and the variables with other distributions were described as median and interquartile range. Categorical variables were compared by Chi-square or Fisher's exact test, and continuous variables by Student $t$ test or Mann-Whitney test. An analysis of agreement between the CACS and the FRS risk assessments was performed using kappa statistic. The reclassification of risk by CACS and based on the FRS was calculated as the percentage of individuals who changed the classification by the CACS stratification. In all analyses, a $\mathrm{p}$ value $<0.05$ was considered significant. The statistical program used was $\mathrm{R}$, version 2.12.1. . $^{31}$ 


\section{RESULTS}

We studied 40 patients, aged $45.9 \pm 8.1$ years, ranging from 31 to 64 years. Only two (5\%) were older than 60 years. Males accounted for $52.5 \%$ of the sample. The demographic and clinical characteristics of studied subjects are shown in Table 1. Two or more risk factors were found in $82.5 \%$ of patients and $5.0 \%$ had five risk factors. The age of risk for CAD was observed in $30.0 \%$ of individuals. A total of $27.5 \%$ individuals had altered blood pressure, and among individuals known to be hypertensive, $50 \%$ showed altered blood pressure. BMI was $25.3 \pm 3.4 \mathrm{~kg} / \mathrm{m}^{2}$, being classified as normal in $50.0 \%$ of subjects, $42.5 \%$ as overweight and obesity in $7.5 \%$. The AC was $89.6 \pm 9.7 \mathrm{~cm}$ in men, and in females, $88.3 \pm 9.7 \mathrm{~cm}$. There were significantly more women than men with altered AC (52.6\% and $4.8 \%$ respectively, $\mathrm{p}=0.001)$.

\section{Table 1. Population characteristics}

\begin{tabular}{lc}
\hline Variable & \\
\hline Age (years) & $45.9 \pm 8.1$ \\
\hline Men & $21(52.5 \%)$ \\
\hline SAH & $22(55.0 \%)$ \\
\hline Type II diabetes & $4(10.0 \%)$ \\
\hline Dyslipidemia & $27(67.5 \%)$ \\
\hline Family history of early CAD & $23(57.5 \%)$ \\
\hline Smoking & $14(35.0 \%)$ \\
\hline Smoking load (pack/years)* & $8.7 *$ \\
\hline AC- men (cm) & $89.6 \pm 9.7$ \\
\hline AC- women (cm) & $88.3 \pm 9.7$ \\
\hline BMI (kg/m²) & $25.3 \pm 3.4$ \\
\hline SBP (mmHg) & $124.2 \pm 21.9$ \\
\hline DBP (mmHg) & $80.0 \pm 10.9$ \\
\hline Glucose (mg/dL) & $100.4 \pm 13.8$ \\
\hline TC (mg/dL) & $188.7 \pm 33.7$ \\
\hline LDL-cholesterol (mg/dL) & $112.5 \pm 28.8$ \\
\hline HDL-cholesterol -men (mg/dL) & $37.0 \pm 11.0$ \\
\hline HDL-cholesterol- women (mg/dl) & $42.6 \pm 11.9$ \\
\hline Triglycerides (mg/dL) & $158.5^{*}$ \\
\hline FRS (\%) & $4.0^{*}$ \\
\hline CACS & $0.0^{*}$ \\
\hline Protease inhibitor use & $21(52.5 \%)$ \\
\hline & \\
\hline
\end{tabular}

*median; SAH, systemic arterial hypertension; CAD, coronary artery disease; AC, abdominal circumference; BMI, body mass index; SBP, systolic blood pressure; DBP, diastolic blood pressure; TC, total cholesterol; LDL, low-density lipoprotein; HDL, high-density lipoprotein; FRS, Framingham Risk Score.
Fasting blood glucose was $100.4 \pm 13.8 \mathrm{mg} / \mathrm{dL}$, and $42.5 \%$ of patients had altered glucose levels $(\geq 100 \mathrm{mg} / \mathrm{dL})$. Regarding the lipid profile, TC was $188.7 \pm 33.7 \mathrm{mg} / \mathrm{dL}$ $(127-268 \mathrm{mg} / \mathrm{dL})$, and $30.0 \%$ of patients had altered TC levels $(\geq 200 \mathrm{mg} / \mathrm{dL})$. LDL-cholesterol was $112.5 \pm 28.8 \mathrm{mg} / \mathrm{dL}$ $(59-184 \mathrm{mg} / \mathrm{dL})$ and was $\geq 130 \mathrm{mg} / \mathrm{dL}$ in $25.0 \%$ of the individuals. HDL-cholesterol was $39.7 \pm 11.6 \mathrm{mg} / \mathrm{dL}$ $(20-71 \mathrm{mg} / \mathrm{dL})$, being $37.0 \pm 11.0 \mathrm{mg} / \mathrm{dL}$ in men and $42.6 \pm 11.9 \mathrm{mg} / \mathrm{dL}$ in women. HDL cholesterol was considered abnormal for age and sex of individuals in $82.5 \%$ and $<40 \mathrm{mg} / \mathrm{dL}$ in $57.5 \%$. Median triglyceride was $158.5 \mathrm{mg} / \mathrm{dL}$ $(43-412 \mathrm{mg} / \mathrm{dL}$, being the first quartile equal to $104.0 \mathrm{mg} / \mathrm{dL}$ and the third quartile, $274.5 \mathrm{mg} / \mathrm{dL}$ ). Triglycerides were altered $(\geq 150 \mathrm{mg} / \mathrm{dL})$ in $52.5 \%$ of the sample.

All patients were on ART, and $52.5 \%$ on PI. Table 2 shows comparisons between patients who were on PI or not. No significant differences were detected, except for altered HDL-cholesterol adjusted for sex, which was more frequent in the group on PI $(\mathrm{p}=0.040)$, and for altered triglycerides, which were more common in individuals who were on PI.

Assessment of cardiovascular risk through the FRS showed that the 10-year risk of MI or death due to CAD had a median of $4.0 \%, 2.0 \%$ in the first quartile and $10.0 \%$ in the third quartile. In this sample, $72.5 \%$ of patients were classified as low risk, $25.0 \%$ as moderate risk and $2.5 \%$ (only one individual) as high risk.

The CACS had a median equal to zero, its value ranging from zero to 632 points. Coronary calcification was found (CACS > 0 ) in $32.5 \%$ of individuals. Patient characteristics according to the presence of coronary calcification are shown in Table 3. Subjects with coronary calcification were significantly older than patients without coronary calcification $(p=0.015)$. However, other significantly different variables were not found between subjects with and without coronary calcification.

According to the percentiles of CACS, $67.5 \%$ of patients had low risk, $17.5 \%$ had moderate risk, and $15.0 \%$ had high risk. The assessment of agreement between the FRS and CACS showed that 22 subjects $(75.8 \%)$ with low FRS were also considered low risk by CACS, 4 (40.0\%) of those with moderate risk by the FRS, had moderate risk by CACS and $100 \%$ of those with high risk by the FRS had high risk by CACS, with a kappa value of 0.435 (Table 4).

\section{DISCUSSION}

Antiretroviral therapy has made HIV infection a chronic condition, and although it is not curable, it is treatable. This fact has allowed the infected population to age and be subject to chronic diseases such as cardiovascular disease, especially CAD. Thus, it is extremely important to know the cardiovascular risk of these patients in order to plan possible interventions that might reduce this risk. The present study assessed patients with HIV infection in order to 
Table 2. Comparisons according to the use of protease inhibitors

\begin{tabular}{|c|c|c|c|}
\hline & $\begin{array}{c}\text { With use } \\
\text { n = } 21 \text { (52.5\%) }\end{array}$ & $\begin{array}{c}\text { Without use } \\
\text { n = } 19(47.5 \%)\end{array}$ & p-value \\
\hline $\mathrm{AC}(\mathrm{cm})$ & $90.4 \pm 11.2$ & $87.4 \pm 7.5$ & 0.336 \\
\hline BMI $\left(\mathrm{kg} / \mathrm{m}^{2}\right)$ & $25.9 \pm 3.9$ & $24.6 \pm 2.8$ & 0.248 \\
\hline Glucose (mg/dL) & $102.2 \pm 12.7$ & $98.5 \pm 14.9$ & 0.404 \\
\hline $\mathrm{TC}(\mathrm{mg} / \mathrm{dL})$ & $192.2 \pm 27.9$ & $184.7 \pm 39.5$ & 0.493 \\
\hline Altered TC & $38.1 \%$ & $21.1 \%$ & 0.240 \\
\hline LDL-cholesterol (mg/dL) & $112.1 \pm 26.5$ & $112.8 \pm 31.8$ & 0.936 \\
\hline LDL-cholesterol < $100 \mathrm{mg} / \mathrm{dL}$ & $33.3 \%$ & $26.3 \%$ & 0.629 \\
\hline HDL-cholesterol (mg/dL) & $38.7 \pm 8.8$ & $40.7 \pm 14.3$ & 0.581 \\
\hline HDL-cholesterol < 40 mg/dL & $57.1 \%$ & $57.9 \%$ & 0.962 \\
\hline Altered HDL-cholesterol & $95.2 \%$ & $68.4 \%$ & 0.040 \\
\hline Triglycerides (mg/dL) & 219.0* & $130.0 *$ & 0.040 \\
\hline Triglycerides $\geq 150 \mathrm{mg} / \mathrm{dL}$ & $71.4 \%$ & $31.6 \%$ & 0.012 \\
\hline FRS (\%) & $4.0 \% *$ & $3.0 \% *$ & 0.375 \\
\hline CACS & $0.0 *$ & $0.0 *$ & 0.782 \\
\hline Coronary calcification & $33.3 \%$ & $31.6 \%$ & 0.906 \\
\hline
\end{tabular}

Value expressed as percentages or mean \pm standard deviation; *median; AC, abdominal circumference; IMC, body mass index; TC, total cholesterol; LDL, low-density lipoprotein; HDL, high-density lipoprotein; FRS, Framingham Risk Score; CACS, coronary artery calcium score.

Table 3. Comparison between patients with or without coronary calcification

\begin{tabular}{lccc}
\hline & $\begin{array}{c}\text { With calcification } \\
\mathbf{n}=\mathbf{1 3}(\mathbf{3 2 . 5 \% )}\end{array}$ & $\begin{array}{c}\text { Without calcification } \\
\mathbf{n = 2 7} \mathbf{( 6 7 . 5 \% )}\end{array}$ & p-value \\
\hline Age (years) & $50.3 \pm 7.3$ & $43.8 \pm 7.7$ & 0.015 \\
\hline Men & $9(42.8 \%)$ & $12(57.1 \%)$ & 0.141 \\
\hline SAH & $8(36.3 \%)$ & $14(63.6 \%)$ & 0.564 \\
\hline Type II diabetes & $2(50.0 \%)$ & $2(50.0 \%)$ & 0.392 \\
\hline Dyslipidemia & $9(33.3 \%)$ & $18(66.6 \%)$ & 0.584 \\
\hline Family history of early CAD & $8(34.7 \%)$ & $15(65.2 \%)$ & 0.720 \\
\hline Smoking & $4(28.5 \%)$ & $10(71.4 \%)$ & 1.000 \\
\hline Smoking load (pack/years) & $5.0^{*}$ & $15.7 *$ & 0.229 \\
\hline AC (cm) & $90.5 \pm 10.3$ & $88.3 \pm 9.3$ & 0.506 \\
\hline BMI (kg/m) & $24.9 \pm 3.1$ & $25.5 \pm 3.6$ & 0.627 \\
\hline SBP (mmHg) & $117.6 \pm 17.3$ & $127.4 \pm 23.5$ & 0.194 \\
\hline DBP (mmHg) & $78.4 \pm 8.7$ & $80.7 \pm 11.9$ & 0.543 \\
\hline Glucose (mg/dL) & $100.1 \pm 14.0$ & $100.1 \pm 13.9$ & 0.833 \\
\hline TC (mg/dL) & $196.6 \pm 32.2$ & $184.8 \pm 34.3$ & 0.309 \\
\hline LDL-cholesterol (mg/dL) & $108.4 \pm 29.5$ & $114.4 \pm 28.8$ & 0.546 \\
\hline HDL-cholesterol (mg/dL) & $39.6 \pm 12.1$ & $39.7 \pm 11.7$ & 0.975 \\
\hline Triglycerides (mg/dL) & $193.0^{*}$ & $140.0^{* *}$ & 0.525 \\
\hline FRS (\% in 10 years) & $8.0 \%^{*}$ & $3.0 \%$ & 0.142 \\
\hline Protease inhibitor use & $33.3 \%$ & $66.6 \%$ & 0.906 \\
\hline
\end{tabular}

*median; SAH, systemic arterial hypertension; CAD, coronary artery disease; AC, abdominal circumference; BMI, body mass index; SBP, systolic blood pressure; DBP, diastolic blood pressure; TC, total cholesterol; LDL, low-density lipoprotein; HDL, highdensity lipoprotein, FRS, Framingham Risk Score. 
Table 4. Agreement between risks assessed by FRS and $C A C S$

\begin{tabular}{lcccc}
\hline & \multicolumn{3}{c}{ CACS } & Total \\
\cline { 2 - 3 } & Low & Moderate & High & \\
\hline FRS & & & & \\
Low & 22 & 3 & 4 & 29 \\
Moderate & 5 & 4 & 1 & 10 \\
High & 0 & 0 & 1 & 1 \\
\hline Total & 27 & 7 & 6 & 40 \\
\hline
\end{tabular}

FRS, Framingham Risk Score; CACS, coronary artery calcium scoring.

determine the prevalence of traditional cardiovascular risk factors, assessing the risk of CAD through previously validated clinical scores and investigate the use of CACS for the diagnosis of subclinical coronary atherosclerosis and as an additional method for risk stratification in this population.

In this sample, the mean age was $45.9 \pm 8.1$ years and only $30 \%$ were at the risk age. Therefore, it can be considered a young population for the development of CAD, but comparable to other studies of populations with HIV. ${ }^{6,30-33}$ However, a high proportion of patients (82.5\%) had two or more traditional risk factors, highlighting the importance of proper stratification of cardiovascular risk in this group. SAH was present in $55 \%$ of patients, being more frequent than in other studies, which showed prevalence rates of $35 \%$ to $41 \%{ }^{34,35}$ and $27.5 \%$ of the patients had altered blood pressure levels. These findings are similar to those found in the general Brazilian population, in which the levels of hypertension control are still suboptimal, ${ }^{18,36}$ indicating the need for greater attention to blood pressure control in the HIV-infected population. ${ }^{18}$

Prevalence of smoking among HIV-infected patients of $47 \%$ to $71 \%$ has been reported, much more elevated than in the general population. ${ }^{34,37}$ The prevalence observed in our sample was $35 \%$ lower than the rates cited above, but still twice the $17.5 \%$ prevalence of the Brazilian population in $2008 .^{38}$ Dyslipidemia was the most frequent risk factor found in $67.5 \%$ of individuals. In the study by Cahn et al., ${ }^{39}$ the prevalence of dyslipidemia in the Brazilian population with HIV infection was $57.3 \%$.

The levels of TC and LDL-cholesterol were slightly higher than the percentage described in the study by Kingsley et al ${ }^{40} \mathrm{HDL}$-cholesterol levels were altered in the majority of the studied population (82.5\%). The study by Kingsley et al. ${ }^{40}$ identified only $40 \%$ of individuals with low HDL-cholesterol, whereas in our population, $57.5 \%$ were identified at this level. However, it is noteworthy that these authors did not take into account the adjustment of HDL-cholesterol according to sex. As for triglycerides, our results are also similar to those previously described (38\%). ${ }^{40}$

In this population, $52.5 \%$ of patients were using PI, which is similar to another Brazilian study. ${ }^{39}$ No significant differences in levels of TC and LDL-cholesterol were found in our sample among individuals using PI or not, similarly to other studies, i.e., minor alterations in these lipid fractions. ${ }^{41-43}$ However, HDL-cholesterol, corrected for age and sex, was significantly more frequent among patients using PI. This difference has been reported in the literature, associated with risk of MI. ${ }^{44}$ It was also possible to demonstrate the association between the use of PI and increased levels of triglycerides, and the median in the group that used PI was $219 \mathrm{mg} / \mathrm{dL}$, compared to $130 \mathrm{mg} / \mathrm{dL}$ in the group that did not use PI. This association has also been previously described. ${ }^{45}$

Risk assessment through the FRS showed that the population of this sample had low risk (FRS median of $4.0 \%$ and the third quartile of $10.0 \%$ ), which can be explained by their age, predominantly young. Notably, one fourth of individuals were classified according to the FRS as having moderate risk, and $2.5 \%$ as having high risk. A significant proportion of individuals with moderate risk underscores the importance of a refinement of risk stratification of this population in order to establish the best treatment and reduce the incidence of adverse cardiovascular events.

Screening for subclinical atherosclerosis through CACS showed that about one third of patients had coronary calcifications, an indicator of the presence of atherosclerosis. Studies carried out in the general population have shown that at the age range of 40-45 years, there is a prevalence of coronary calcification of $13.3 \%$ to $21 \%{ }^{46,47}$ The frequency of calcification found in this sample was similar to the study by Crum-Cianflone et al. ${ }^{48}$ among individuals with HIV infection, in which $34 \%$ of patients showed calcification in the coronary arteries. Patients with calcification in the coronary arteries were significantly older than those without calcification, which has been shown in other studies of patients with and without HIV infection. . $^{32,40,47,49}$ Although other studies have already reported an association between coronary calcification in individuals with HIV and other variables (SBP, triglycerides, TC, smoking, FH of CAD, dyslipidemia) ${ }^{30,40}$ these associations were not found in our population, possibly due to the small sample size.

The agreement between the risk stratification by FRS and the CACS showed a kappa of 0.435 . In this study, we did not have access to the clinical follow-up of patients, and therefore could not make any inference regarding the accuracy of these two forms of risk stratification to predict the occurrence of events. Although it was not possible to establish the best score for risk prediction in this population, it 
was possible to verify the frequency of modifications in risk classes defined by the FRS provided by CACS. The reclassification of risk occurred in $32.5 \%$ of individuals, and from the category of low risk by FRS, $24 \%$ had their risk increased ( $10.3 \%$ to moderate risk and $13.7 \%$ to high risk). From the category of moderate risk (the most widely described as the main indication for refinement of risk assessment), 10\% had their risk increased and 50\% had the risk decreased.

The effect of CACS on moderate-risk individuals by the FRS was consistent with published data, which showed a higher frequency of reclassifications exactly in this category. ${ }^{50-52}$ This capacity of CACS makes it attractive to refine risk stratification in the HIV-infected population. For individuals considered high risk by CACS, the therapeutic approach would possibly be changed. ${ }^{8,11}$

\section{CONCLUSIONS}

One of the limitations of the study was the unavailability of data like the time of HAART, use of PI and HIV infection, which may be correlated with the occurrence of CAD. Larger studies with long-term clinical followup are necessary to confirm the findings and allow obtaining a precise risk score, specific for the needs of this population.

\section{REFERENCES}

1. The Joint United Nations Programme on HIV/AIDS. UNAIDS. AIDS epidemic update [Internet]. Geneva: [updated on 2010; cited 2011 Jan 11]. Available from: http://www.unaids. org/en/media/unaids/contentassets/documents/unaidspublication/2010/20101123_globalreport_en[1].pdf

2. Ministério da Saúde. Aids.gov: Aids no Brasil [Internet]. Brasília: Ministério da Saúde. [cited 2011 Jan 11]. Available from: http://www.aids.gov.br/pagina/aids-no-brasil

3. Ministério da Saúde. Monitoraids [Internet]. Brasília: Ministério da Saúde [cited 2011 Jan 10]. Available from: http://sistemas.aids.gov.br/monitoraids/?keyWord=gasto\&condicaoFich $\mathrm{a}=$ nomeIndicador\&desagregacao $=1$

4. Lohse N, Hansen AB, Pedersen G, et al. Survival of persons with and without HIV infection in Denmark, 1995-2005. Ann Intern Med. 2007; 146(2):87-95.

5. Currier JS, Taylor A, Boyd F, et al. Coronary heart diseases in HIV- infected individuals. J Acquir Immune Defic Syndr. 2003; 33:506-12.

6. Triant VA, Lee H, Hadigan C, Grinspoon SK. Increased acute myocardial infarction rates and cardiovascular risk factors among patients with human immunodeficiency virus disease. J Clin Endocrinol Metab. 2007; 92;2506-12.

7. D'Arminio A, Sabin CA, Phillips AN, et al. Writing Committee of the D:A:D: Study Group. Cardio and cerebrovascular events in HIV-infected persons. AIDS. 2004; 18:1811-7.

8. Sposito AC, Caramelli B, Fonseca FA, et al. Sociedade Brasileira de Cardiologia. IV Brazilian Guideline for Dyslipidemia and Atherosclerosis prevention: Department of Atherosclerosis of Brazilian Society of Cardiology. Arq Bras Cardiol. 2007; 88(Suppl 1):2-19.
9. Grupo de Estudo em Ressonância e Tomografia Cardiovascular (GERT) do Departamento de Cardiologia Clínica da Sociedade Brasileira de Cardiologia. Cardiovascular magnetic resonance and computed tomography imaging guidelines of the Brazilian Society of Cardiology. Arq Bras Cardiol. 2006; 87(3):e60-100.

10. Ministério da Saúde, Secretaria de Vigilância em Saúde, Programa Nacional de DST e Aids. Recomendações para terapia anti-retroviral em adultos infectados pelo HIV:2008. Brasília: Ministério da Saúde; 2008.

11. National Cholesterol Education Program (NCEP) Expert Panel on Detection, Evaluation, and Treatment of High Blood Cholesterol in Adults (Adult Treatment Panel III). Third Report of the National Cholesterol Education Program (NCEP) Expert Panel on Detection, Evaluation, and Treatment of High Blood Cholesterol in Adults (Adult Treatment Panel III) final report. Circulation. 2002; 106:3143-421.

12. Rodbard HW, Blonde L, Braithwaite SS, et al. AACE Diabetes Mellitus Clinical Practice Guidelines Task Force. American Association of Clinical Endocrinologists medical guidelines for clinical practice for the management of diabetes mellitus. Endocr Pract. 2007; 13(Suppl 1):1-68.

13. American Diabetes Association. Standards of medical care in diabetes-2006. Diabetes Care. 2006; 29(Suppl 1):S4-S42.

14. Bailey KV, Ferro-Luzzi A. Use of body mass index of adults in assessing individual and community nutritional status. Bull World Health Organ. 1995; 73:673-80.

15. National Institutes of Health. Clinical guidelines on the indentification, evaluation, and treatment of overweight and obesity in adults - the evidence report. Obesity Res. 1998; 6(suppl 2):51S-209S.

16. Janssen I, Katzmarzyk PT, Ross R. Waist circunference and not body mass index explains obesity-related health risk. Am J Clin Nutr. 2004; 79:379-84

17. Lohman TG, Roche AF, Martorell R. Anthropometric standardization reference manual. Champaign: Human Kinetics Book; 1998

18. Sociedade Brasileira de Cardiologia, Sociedade Brasileira de Hipertensão, Sociedade Brasileira de Nefrologia. VI Diretriz Brasileira de Hipertensão Arterial. Arq Bras Cardiol. 2010; 95(1 suppl1):1-51.

19. American Diabetes Association. Screening for type 2 diabetes. Diabetes Care. 2004; 27(Suppl 1):S11-S4.

20. Castelli WP. Cardiovascular disease and multifactorial risk: challenge of the 1980s. Am Heart J. 1983; 106:1191-200.

21. Achenbach S, Daniel WG. Tomografia Computadorizada do Coração. In: Braunwald E, Zipes DP, Libby P, Bonow RO. Braunwald tratado de doenças cardiovasculares. $7^{\mathrm{a} e d . ~ P h i l a d e l p h i a: ~}$ Elsevier Saunders; 2006. p. 355-371.

22. Agatston AS, Janowitz WR, Hildner FJ, et al. Quantification of coronary artery calcium using ultrafast computed tomography. J Am Coll Cardiol. 1990; 15(4):827-32.

23. Rumberger JÁ, Kaufman L. A rosetta stone calcium risk stratification: Agatston, volume, and mass score in 11,490 individuals. AJR Am J Roentgenol. 2003; 181:743-8.

24. Nasir K, Raggi P, Rumberger JA, et al. Coronary artery calcium volume scores on electron beam tomography in 12,936 asymptomatic adults. Am J Cardiol. 2004; 93:1146-9.

25. Hoff JA, Chomka EV, Krainik AJ, et al. Age and gender distributions of coronary artery calcium detected by electron beam tomography in 35,246 adults. Am J Cardiol. 2001; 87:1335-9.

26. Rumberger JA, Brundage BH, Rader DJ, et al. Electron beam computed tomographic coronary calcium scanning: a review and guidelines for use in asymptomatic persons. Mayo Clin Proc. 1999; 74:243-52. 
27. Sociedade Brasileira de Cardiologia. Departamento de Cardiologia Clinica. Grupo de Estudo de Ressonância e Tomografia Cardiovascular (GERT). Guideline of Sociedade Brasileira de Cardiologia for resonance and cardiovascular tomography. Exucutive summary. Arq Bras Cardiol. 2006; 87(Suppl 3):e1-e12.

28. O’Rourke RA, Brundage BH, Froelicher VF, et al; American College of Cardiology/American Heart Association Expert consensus document on electron-beam computed tomography for the diagnosis and prognosis of coronary artery disease. Circulation. 2000; 102:126-40.

29. Truett J, Cornfield J, Kannel W. A multivariate analysis of the risk of coronary heart disease in Framingham. J Chronic Dis. 1967; 20:511-24.

30. D'Agostino RB Sr, Grundy S, Sullivan LM, et al. Validation of the Framingham coronary heart disease prediction scores: results of a multiple ethnic groups investigation. JAMA. 2001; 286:180-7.

31. R Development Core Team (2011). R: A language and environment for statistical computing. R Foundation for Statistical Computing, Vienna, Austria. ISBN 3-900051-07-0, URL http://www.R-project.org/

32. Mangili A, Gerrior J, Tang AM, et al. Risk of cardiovascular disease in a cohort of HIV-infected adults; a study using carotid intima-media thickness and coronary artery calcium score. Clin Infect Dis. 2006; 43:1482-9.

33. Mangili A, Gerrior J, Tang AM, et al. Metabolic syndrome and subclinical atherosclerosis in patients infected with HIV. Clin Infect Dis. 2007; 44:1368-74.

34. Steinn JH, Hadigan CM, Brown TT, et al. Prevention strategies for cardovascular disease in HIV-infected patients. Circulation. 2008; 118:e54-e60.

35. Kaplan RC, Kingsley LA, Sharrett AR, et al. Ten-year predicted coronary heart disease risk in HIV-infected men and women. Clin Infect Dis. 2007; 45:1074-81.

36. Rosáorio TM, Scala LCNS, França GVA, et al. Prevalência, controle e tratamento da hipertensão arterial sistêmica em Nobres - MT. Arq Bras Cardiol. 2009; 93:672-8.

37. Gritz ER, Vidrine DJ, Lazev AB, et al. Smoking behavior in a low-income multiethnic HIV/AIDS population. Nicotine Tab Res. 2004; 6:71-7.

38. Ministério da Saúde. INCA. Publicações, e Pesquisa nacional por amostra de domicílio/tabagismo [internet]. Brasília: Ministério da saúde. [cited 2011 Jan 15]. Available from: http://www.inca.gov.br/inca/Arquivos/publicacoes/tabagismo.pdf

39. Cahn P, Leite O, Rosales A, et al. Metabolic profile and cardiovascular risk factors among Latin American HIV-infected patients receiving HAART. Braz J Infect Dis. 2010; 14:158-66.

40. Kingsley LA, Cuervo-Rojas J, Muñoz A, et al. Subclinical coronary atherosclerosis, HIV infection and antiretroviral therapy: Multicenter AIDS Cohort Study. AIDS. 2008; 22:1589-99.
41. Mulligan K, Grunfeld C, Tai VW, et al. Hyperlipidemia and insulin resistance are induced by protease inhibitors independent of changes in body composition in patients with HIV infection. J Acquir Immune Defic Syndr. 2000; 23:35-43.

42. Periard D, Telenti A, Sudre P, et al. Atherogenic dyslipidemia in HIV-infected individuals treated with protease inhibitors: the Swiss HIV Cohort Study. Circulation. 1999; 100:700-5.

43. van der Valk M, Kastelein JJ, Murphy RL, et al. Nevirapine-containing antiretroviral therapy in HIV-1 infected patients results in anti-atherogenic lipid profile. AIDS. 2001; 15:5186-92.

44. Duprez DA, Kuller LH, Tracy R, et al. Lipoproteina particle subclasses, cardiovascular disease and HIV infection. Atherosclerosis. 2009; 207:524-9.

45. Danner SA, Carr A, Leonard JM, et al. A short-term study of the safety, pharmacokinetics, and efficacy of ritonavir, na inhibitor of HIV-1 protease. European-Australian Collaborative Ritonavir Study Group. N Engl J Med. 1995; 333:1528-33.

46. Davis PH, Dawson JD, Mahoney LT, et al. Increased carotid intimal-medial thickness and coronary calcification are related in young and middle-aged adults: The uscatine study. Circulation. 1999; 100:838-42.

47. Loria CM, Liu K, Lewis CE, et al. Early adult risk factor levels and subsequent coronary artery calcification: the CARDIA study. J AM Coll Cardiol. 2007; 49:2013-20.

48. Crum-Cianflone N, Stepenosky J, Medina S, et al. Clinically significant incidental findings among human immunodeficiency virus-infected mem during computed tomography for determination of coronary artery calcium. Am J Cardiol. 2011; 107:633-7.

49. McClelland RL, Chung H, Detrano R, et al. Distribution of coronary artery calcium by race, gender, and age: results from Multi-Ethnic Study of Atherosclerosis (MESA). Circulation. 2006; 113:30-7.

50. Greenland $\mathrm{P}$, Bonow RO, Brundage $\mathrm{BH}$, et al. ACCF/AHA 2007 clinical expert consensus document on coronary artery calcium scoring by computed tomography in global cardiovascular risk assessment and in evaluation of patients with chest pain: a report of the American College of Cardiology Foundation Clinical Expert Consensus Task Force (ACCF/AHA Writing Committee to Update the 2000 Expert Consensus Document on Electron Beam Computed Tomography) developed in collaboration with the Society of Atherosclerosis Imaging and Prevention and the Society of Cardiovascular Computed Tomography. J Am Coll Cardiol. 2007; 49:378-402.

51. Raggi P, Shaw LJ, Berman DS, et al. Prognostic value of coronary artery calcium screening in subjects with and without diabetes. J Am Coll Cardiol. 2004; 43:1663-9.

52. Raggi P, Cooil B, Callister TQ. Use of electron beam tomography data to develop models for prediction of hard coronary vents. Am Heart J. 2001; 141:375-82. 